\title{
Climate-Sensitive Urban Design Measures for Improving the Wind Environment for Pedestrians in a Transit-Oriented Development Area
}

\author{
Chunming Hsieh (Corresponding author) \\ Department of Urban Planning, College of Planning and Design, National Cheng Kung University \\ No.1, University Rd., Tainan 70101, Taiwan \\ Tel: 886-6-275-7575 E-mail: chunming@mail.ncku.edu.tw \\ Kangli Wu \\ Department of Urban Planning, School of Architecture, Harbin Institute of Technology \\ 1532 \#, No. 66 Xi Dazhi Street, Nan Gang Dist, Harbin 150006, China \\ Tel: 86-451-8628-1137Ｅ-mail:.wgl@hit.edu.cn
}

Received: January 20, 2012 Accepted: March 1, $2012 \quad$ Published: April 1, 2012

doi:10.5539/jsd.v5n4p46

URL: http://dx.doi.org/10.5539/jsd.v5n4p46

The research is financed by National Science Council of Taiwan: NSC 99-2221-E-006-177-MY2

\begin{abstract}
This study examines the blocks around the main station of the Kaohsiung Railway Underground Project in which the $400 \mathrm{~m}$ around station will be redeveloped. Two concepts, sustainable urban design and TOD (transit oriented development), were integrated to develop a new planning approach called the original Green-TOD. Among the key issues of Green-TOD, the relation between pedestrian space design and air ventilation is a crucial issue for providing pedestrians with amenities in a tropical climate like Kaohsiung. In this study, wind speed and wind direction, which were selected from the two main high traffic periods during the summer, served as the primary simulation settings of computational fluid dynamics (CFD), and wind distribution between roadside-based and street-block-based developments were compared. Major implemented policies for urban design, including the incentives for floor area ratio (FAR), building mass and layout, and open space design measures, are explicitly addressed as well. The results of the CFD simulation show the quality of the ventilation can be improved through land-use control measures.
\end{abstract}

Keywords: Wind environment, Pedestrian space, CFD (computational fluid dynamics), TOD (transit oriented development), Urban design, FAR (floor area ratio)

\section{Introduction}

Transit oriented development (TOD) is a planning concept that aims to provide livable and sustainable urban environments through developing mixed land use and better pedestrian environment within walking distance of public transit stations. In general, the basic ideas of TOD is to design a relatively high density, compact and mixed-used urban form, and to provide high quality, efficient mass transportation services together with a pedestrian friendly environment (Cervero, 2002; Loo et al., 2010; Sung \& Oh, 2011). On the district level in particular, TOD aims at creating compact and compatible mixed land use and developmental patterns within walking distance of rail stations. It is advocated that, around the stations, various daily services and residential buildings are built according to appropriate urban design control in hope of attracting ample and diversified population and urban activities (Atkinson-Palombo \& Kuby, 2011; Bernick \& Cervero, 1997; Calthorpe, 1993).

A high density development in urban areas, however, affects the ventilation of buildings as well as the comfort and safety of pedestrians. Tall and bulky high-rise building blocks with limited open spaces between them, uniform building heights, and large podium structures lead to lower permeability for urban air ventilation at the pedestrian level $(\mathrm{Ng}, 2009)$. Five classifications of the pedestrian wind speed were assigned in Hong Kong (Yuan et al., 2012). These classifications denote stagnant $(\mathrm{v}<0.3 \mathrm{~m} / \mathrm{s})$, poor $(0.3<\mathrm{v} \leq 0.6 \mathrm{~m} / \mathrm{s})$, low $(0.6<\mathrm{v} \leq 1.0 \mathrm{~m} / \mathrm{s})$, satisfactory $(1.0<\mathrm{v} \leq 1.3 \mathrm{~m} / \mathrm{s})$ and $\operatorname{good}(\mathrm{v} \geq 1.3 \mathrm{~m} / \mathrm{s})$ pedestrian-level natural ventilation in street canyons, 
respectively. It is widely accepted that an increase in building density reduces wind speed in urban areas (Kubota et al., 2008; Rafailidis, 1997). In such a scale, air flow is influenced by various factors, such as upstream terrain conditions and wind direction. Wind corridors can result from roads, open spaces, and passages through which air reaches the interiors of urbanized areas. Urban wind research has investigated turbulent flow conditions in different street canyon models (Ng et al., 2011; Oke, 1988; Xie et al., 2006). Building configuration (e.g., height, width, arrangement, and density) are the significant factors affecting wind at ground level (Baruch, 1998; Willemsen \& Wisse, 2007). The reduction in wind velocity caused by building density is due to increased friction near the ground (Capeluto, 2003). Building arrangement is an important consideration for planners and designers seeking to improve the wind environment. Therefore, it is necessary to understand the pedestrian wind environment around buildings and take them into account in urban design (Kubota et al., 2008; Mochida \& Luna, 2008).

TOD increases the efficiency and accessibility of locations and encourages people to use public transportation instead of private vehicles for daily commuting. In theory and practice, TOD and ecological community are good tools for implementing sustainable urban design (Cervero \& Day, 2008; Millward, 2004; Walmsley, 2006). A number of recent studies attempt combine the concept of TOD and ecological urban design as well as ecological communities to develop a new planning approach named Green-TOD (Wu, 2009). The Green transit oriented development (Green-TOD) concepts attempt to combine the traditional TOD model with the concept of ecological community as well as eco-cities in order to develop a planning model that promote the accessibility, livability, diversity, and ecological integrity of the areas served by transit services (Wu, 2009). It also advocates the use of new methods and technologies for creating livable urban places with sustainable land-use planning and pedestrian space design in order to reduce climate impact. Green-TOD considers many perspectives.

This study used the areas around the main rail station of the Urban Design Project of Kaohsiung Railway Underground Development as an example to explore how to address the issue of wind environment and climate-sensitive urban design in rail station areas under the concept of Green-TOD, which integrates the idea of transit-oriented development and living environment as well as pedestrian space design. The urban design project of the underground development of rail system include an urban regeneration project that aims at adjusting urban design elements of the existing railway corridor and station areas in order to promote the concept of Green-TOD. Through the urban redevelopment and adjustment of zoning and urban design control in selected blocks, the goal of the project is to promote the vitality and livability of the station areas and to improve the land use efficiency in the rail corridor areas.

The relationship between wind environment and urban design was addressed on the district scale. This is particularly critical in large cities located in subtropical and tropical climates in Taiwan. Specific climatic conditions within the urban canopy were influenced by the urban design policy of the local area. Control of FAR and building masses were the main considerations explicitly addressed in this paper since they are two of the key issues when implementing the concept of TOD in the area around the railway station. The wind distribution of the current situation was first analyzed. Then cases were discussed around the station according to the various urban design policies in the control of building mass and layout. The ways in which different building height scenarios and building layouts affect the directions of the prevailing winds are discussed further. To address the issue of climate sensitive-design in urban design control, computational fluid dynamic (CFD) simulations were used to examine the wind environments in different building design scenarios in the blocks around rail station.

The rest of this paper is organized as follows. Section 2 introduces the research methodology, including the CFD model, simulation validation. Terms related to the simulation are also defined. The four simulation cases are explained and the microclimate simulation results are given in Section 3. Decision of urban design measures are discussed in Section 4, and conclusions are given in Section 5.

\section{Data and Methods}

\subsection{Study Area and Local Meteorological Data Analysis}

Figure 1 shows the location of the focus area in Kaohsiung City. Kaohsiung $\left(22^{\circ} 36^{\prime} 09 \mathrm{~N}, 120^{\circ} 18^{\prime} 64 \mathrm{E}\right)$ is located in southern Taiwan, of about 1 degree south of the Tropic of Cancer. The administrative area of the city is about $2,950 \mathrm{~km}^{2}$ and the urbanized area (urban planning area) is around $147 \mathrm{~km}^{2}$. Kaohsiung City, with a population of about 2.77 million, is the second largest city in Taiwan. Previously a port-based industrial city, it has now been transformed into a multi-functional metropolis. During the process of adjustment of urban form, land use, and industrial structure of the city, the urban design of the areas around the rail stations plays an important role in linking the land use and urban activities which are previously segregated by the rail system.

The existing urban policies of Kaohsiung strongly support TOD in the rail corridor and areas around stations. For 
example, to promote compact and planed development around rail station and to attract desired urban activities, the existing urban design regulations is modified to allow for the floor area ratio (FAR) of the blocks located within 400 meters of the Kaohsiung railway stations be increased by $30 \%$. The content and lot size of land use in the blocks is also adjusted in order to attract desired business and residential activities. However, for a district with an average block FAR of about $400 \%$ and a average building coverage ratio (BCR) about $70 \%$, the urban environment surrounding Kaohsiung station will be significantly influenced by such a change without carefully studying the relationship between urban design and micro-climate environment. Therefore, concepts of wind corridors and climate sensitive urban design (e.g., considering building floor area, masses, height, and building setback, and the location of open space together with micro-climate) should be employed to make the pedestrian space and block living environment more comfortable.

In terms of climate condition, Kaohsiung City has a tropical monsoon and tropical marine climate in which summer is the rainy season. In this urban climate investigation, hourly data was obtained from the Kaohsiung Meteorological Station, and the air temperature was analyzed monthly from 2001 to 2010. Figure 2(a) shows that June, July, August, and September are the hottest months of the year. July is the month has the highest average temperature $\left(29.33^{\circ} \mathrm{C}\right)$, followed by August $\left(28.93^{\circ} \mathrm{C}\right)$, and January has the lowest temperature $\left(19.58^{\circ} \mathrm{C}\right)$.

In order to increase the comfort of pedestrian, high traffic periods (those in which there are a lot of people on the street) were selected as the primary simulation settings. According to statistics about people entering and leaving Kaohsiung Railway Station and Kaohsiung MRT Station, (IOT, MOTC, 2010), there is one rush hour in the morning, from 07:01 to 09:00, and one rush hour in the afternoon, from 15:01 to 21:00. Studying wind speed and wind direction analyses (Figures 2(b) and (c)), the prevailing wind from 07:01-09:00 during the summer is a southerly wind, occupying $16.33 \%$ of the sixteen wind directions. The prevailing wind from 15:01-21:00 during the summer is a northwesterly wind, occupying $17.30 \%$ of the sixteen wind directions. Local meteorological data was chosen as the factor for boundary conditions in CFD simulations. The analyzed figures were used in the simulation model.

\subsection{Simulation Cases and Focus Areas}

The geometry of the CFD simulation and boundary of the computational domain are shown in Figure 3 . The entire simulation boundary was $1500 \mathrm{~m}(\mathrm{~N}-\mathrm{S}) \times 1500 \mathrm{~m}(\mathrm{E}-\mathrm{W}) \times 600 \mathrm{~m}$ (altitude), and the studied site in each case covered an area of $800 \mathrm{~m}(\mathrm{~N}-\mathrm{S}) \times 800 \mathrm{~m}(\mathrm{E}-\mathrm{W})$. The computational domain was constructed with a vertical length of $3 \mathrm{H}$, and lateral and upwind lengths of more than $3 \mathrm{H}$. The size of the finest meshes, located at the center of simulation area, was $2 \mathrm{~m} \mathrm{x} 2 \mathrm{~m}$ on the $\mathrm{x}$ and y axes, respectively. The mesh size gradually became coarser (in increments of 3,5, and $10 \mathrm{~m}$ ) moving from the center to the edge. The vertical axis was set at $0.5 \mathrm{~m}$ in the focus areas, and gradually increased with height. The total mesh number for the simulation was more than three million. Wind speed as a function of height above the ground was assumed to follow a power law distribution. The exponent was set to 0.27 , which is the value commonly used for city areas. In the discussions of the following cases $a$ and $b$ indicate the times 07:01-09:00 and 15:01-21:00, respectively, during the summer. The prevailing wind from 07:01-09:00 during the summer is a south wind with a main speed of $2.33 \mathrm{~m} / \mathrm{s}$; the prevailing wind from 15:01-21:00 during the summer is a northwest wind, with a main speed of $2.88 \mathrm{~m} / \mathrm{s}$. Boundary conditions are shown in Table 1.

After the completion of Kaohsiung Railway Underground Project and the proposed urban regeneration project, two proposed skyscrapers on north side of the road (shown in Figure 4) will be constructed to serve as the major landmarks in the district. Therefore, except for the analysis of current situation, Case 0 , the influence of the two high-rising buildings on local wind environment will be taken into consideration in the other cases in order to suggest better urban design control in this area to mitigate the impact they may cause.

Four situations were studied based on different assumptions of the layout and height of new buildings after urban regeneration. The first one is assumed that the new buildings of the first phase of development will be developed along the main corridor (along the streets bounded by the dashed line), and this is named the pattern of roadside-based development, as shown in Case 1. The second one is assumed that the new development of buildings is conducted by a control of the total FAR of each block (common used in local urban design control), and this is implemented in the streets blocks in the area bounded by the solid line. This is named the pattern of street-block-based development, as shown in Case 2. The detailed illustration of the focus areas above is shown in Figure 5. Further discussion about the impacts of seasonal prevailing winds and buildings in windward areas on leeward areas are presented in Cases 3 and 4. In Case 3, the control simulation settings remain the same, while the heights of the buildings are altered, based mainly on our study of wind effect; in Case 4, building layout is altered based on a consideration of the relationship between wind environment and the layout of open 
space. It should be noted that all cases mentioned above were manipulated using the same total floor area in the focus areas, since this is an important market concern in land development in practice.

\subsection{Simulation Validation}

To prove the results of the Wind Tunnel Test and the CFD simulation, the Wind Tunnel Test done by Niigata Institute of Technology in Japan was used as the verifying data; the main wind directions-NNE and west (Figure 6 )-were used as the simulative conditions (Tominaga, 2008). The smallest mesh was $2 \mathrm{~m} \times 2 \mathrm{~m}$, and the boundary size was the same as the settings in this study. A similar grid mesh methodology was proposed, and the verification of the CFD model showing good agreement was confirmed using measurement data in an urban area. Details about the settings of the Wind Tunnel Test are elaborated on in the references. The results revealed that the wind speed of the Wind Tunnel Test was close to that of the CFD simulation, proving the credibility of the simulation's results (Figure 7).

\section{Simulation Results}

\subsection{Case 0: Current Situation (No High-Rise Building Development)}

Figure 8(a) shows a 3D vertical view of the whole area, and Figure 8(b) is the transect map from point $\mathrm{x}$ to $\mathrm{x}$ '. Figures 8(c) and (d) show the present wind distribution of summer morning (Case $0-a)$ and early evening (Case 0 -b) respectively in areas surrounding the Kaohsiung railway station at a height of $1.5 \mathrm{~m}$. In the current situation, the railway and platform of the Kaohsiung station run west to east and there is a bridge crossing north to south above the railway station. A lower wind speed was observed below the bridge than above the bridge revealing that blocks street ventilation. The simulation results indicated that wind speed was relatively slow inside the focus areas due to the narrow width of the street in Case 0-a. When the wind comes from the NW in Case 0-b, higher wind speeds above the railway and the station plaza were found. However, poor ventilation was observed on the sidewalk for pedestrian around the railway station.

\subsection{Case 1: Roadside-Based Development}

Figure 9(a) shows a 3D vertical view of the whole area. It clearly shows that new buildings are arranged along the roadside (the main corridor)-that is, a roadside-based development was applied. Figure 9(b) shows the transect map from point $x$ to $x$ '. Figures $9(\mathrm{c})$ and $(\mathrm{d})$ show the wind distribution of south wind (Case 1-a) and northwest wind (Case 1-b) in Case 1 respectively, both at the height of $1.5 \mathrm{~m}$. Case 1 simulates the situation that there is a high density of buildings along the roadside. The plaza space between the two skyscrapers is located in the center of the simulation boundary. The skyscrapers are longer in the north-south direction, which induced the average wind speed on north-south running roads increased. An obvious difference between the situation in the morning and that in the evening was found. In Case 1-a, the wind speed on west-east running roads was much lower than that on roads running north-south. The wind speed was found slow on the leeward side of the buildings because of the east-west running roadside-based development. It can be seen that roadside-base arrangement hinders the formation of a wind corridor and results in worse ventilation.

\subsection{Case 2: Street-Block-Based Development}

Figure 10(a) shows a 3D vertical view of the whole area. In this case, buildings were arranged in the form of street blocks; that is, a street block-based development was applied. Figure 10(b) is the transect map from point $\mathrm{x}$ to $x$ '. Figures 10(c) and (d) show the wind distribution of south wind (Case 2-a) and northwest wind (Case 2-b) in Case 2, at the height of $1.5 \mathrm{~m}$. There were no buildings on the south side of the focus areas and wind coming from the south flowed directly into the focus areas in Case 2-a. However, a lower wind speed was observed on roads running east-west. In Case 2-b, better ventilation was also observed in the north-south direction although the prevailing wind was coming from the northwest. Improved wind speed was found on the sidewalk inside the focus areas. On the whole, the wind speed in Case 2 was greater than that in Case 1. However, the average wind speed on roads running east-west was much smaller that on roads running north-south in both Cases 2-a and 2-b. To improve pedestrian comfort, Case 3 was drafted to increase wind speed on roads running east-west.

\subsection{Case 3: Street-Block-Based Development with Different Building Heights}

It was found in the simulation that ventilation varies on roads that run in different directions. Therefore, Case 3 proposes a scenario with different building heights concerning prevailing wind directions. It can be seen in the $3 \mathrm{D}$ vertical view of the area in Figure 11(a) and the transect map from point $\mathrm{x}$ to $\mathrm{x}$ ' in Figure 11(b). Based on the arrangements of buildings in the previous case, buildings are further designed by different height according to local environment in this case. Inside the building construction block, buildings on south side are built shorter than those on north side, and buildings on west side are built shorter than those on east side since the prevailing wind comes from west and northwest. 
Figures 11(c) and (d) show the wind distributions of south wind (Case 3-a) and northwest wind (Case 3-b) respectively in Cases 3 at the height of $1.5 \mathrm{~m}$. Although lower wind speeds on roads running north-south were found in Case 3-a than in Case 2-a, the more wind was found on roads running east-west in Case 3-a. People enjoy almost the same wind speed no matter they are walking on roads running east-west or roads running north-south. However, in case 3-b, when the wind is coming from the northwest, the buildings on east side of the skyscrapers are on the leeward side so that the ventilation is influenced by the design of the skyscrapers. The north-south oriented skyscrapers caused winds to shift to north-south wind so that wind cannot blow into street blocks through roads running east-west. From the simulation results, the wind speed on the roads running east-west is observed lower than that on roads running north-south.

Different building heights in the focus area induced the prevailing wind to flow at the pedestrian level differently. The simulation results revealed that higher buildings on north and east sides induced better ventilation at pedestrian level in Cases 3-a and 3-b. Better ventilation in Case 3 were observed compared with Case 2. This indicates that if buildings' heights are adjusted so that the buildings on windward side are shorter, ventilation will then be effectively increased. However, when the prevailing wind is northwesterly, the average wind velocities on roads running east-west and roads running north-south still differ significantly. Consequently, Case 4 was designed to rectify this problem.

\subsection{Case 4: Street-Block-Based Development with a Different Building Layout}

From the analysis of the previous case's simulation results, it can be seen that different building mass control should be applied on opposite sides of the skyscrapers to create a better wind environment. The shapes of the skyscrapers increase wind speed on roads running north-south. However, in Case 4, the goal is to increase wind speed in pedestrian spaces running east-west for eastern blocks. Case 4 uses the building heights from Case 3 and adjusts the open space of each building within that area. On the east side of the high-rise buildings, there was more open space on the north side by transferring floors areas from building on the north side to buildings on the south side. The total floor areas of building in street blocks were not changed. Figures12(c) and (d) also show the wind distribution of south wind and northwest wind in Case 4 at a height of $1.5 \mathrm{~m}$ as well. In Case $4-\mathrm{a}$, the airflow on the east side of the building was induced into moving east-west. A stronger wind was found on roads running east-west in Case 4-a than in Case 3-a. In Case 4-b, although the wind was coming from south, ventilation on roads running east-west was also improved. Compared with Case 3-b, the average wind speed on roads running east-west actually increased because of the building arrangement. The simulation results revealed that the wind environment improved and wind flows onto the pedestrian areas because of the variation in building line and reservation of open spaces. In this way, the prevailing winds, both southerly and northwesterly, could flow into the street blocks more easily.

\subsection{General Discussions}

Figure 13 shows the average wind speeds for all cases discussed in this paper. During the urban redevelopment period, differences in average wind speed in the focus areas were calculated in Cases 1-4. Better ventilation was found in Case 2 than in Case 1 showing the potential for a wind corridor in Case 2 was higher. Therefore, street-block-based development was decided for the following discussions. However, the wind speeds on roads running east-west were slower than those on roads running north-south. Building heights were altered according to the direction of the prevailing wind in Case 3 in order to enhance ventilation. Small differences in wind speed on roads in both directions were observed in Case 3-a, which indicated that people would enjoy nearly the same ventilation when walking on roads running in different directions. However, there is an obvious difference between the average wind speed on roads running east-west and on roads running in Case 3-b. Building size and arrangement of open spaces for eastern blocks were then both altered according to the airflow around the skyscrapers. Finally, the best ventilation for the sidewalks in the focus areas was found for both prevailing wind directions in Case 4.

\section{Decision of Urban Design Measures}

Based on our empirical study, it is found that Green-TOD approach enables the realization of climate-sensitive urban design by controlling building mass and layout. Based on previous empirical findings, some urban design measures are suggested as follows:

\subsection{Street Block Design}

Local wind environment and the continuity of wind corridors should be maintained when dividing street blocks. To retain the smoothness of the wind corridor, appropriately proportioned building lines and roads should be assigned along the sides of the wind corridor in accordance with urban design regulations. Street blocks should 
not be so narrow that they reduce wind speed. According to the comparisons shown in Case 1 and Case 2 , it was found that roads running east-west are not available to form wind corridor when the prevailing wind comes from south.

\subsection{Building Mass Control}

Building form, site plan, building setback, and the organization of building mass too should all be considered when implementing local wind control. Immense differences in size should be avoided. When there have been already two high-rise buildings, the layouts and heights of the surrounding buildings should be adjusted. Arranging shorter buildings on the windward side enables the prevailing wind to enter and flow through the open areas in the street blocks, like in Case 3. This also decreases ground eddies, which occur when wind passes through high-rise building masses. Moreover, it is also possible to make use of street planting to create a comfortable wind environment for residents.

\subsection{Open Space Setting}

Depending on the direction of the prevailing wind, open spaces, such as plazas and street corners, on the windward side may cause the wind to blow into interior of blocks, creating a more comfortable microclimate. Therefore, the layouts of open spaces should consider the prevailing winds first. As is discussed in Case 4, both sides of street blocks on the both sides of the high-rise buildings are designed respectively under such a concern.

In summary, to implement the concept of Green-TOD, urban design should take microclimate environments into account when considering the wind corridor effect, building a mass control, building setbacks, creating greening strategies, and allocating urban plazas, in order to create more comfortable and livable community environments.

\section{Conclusions}

Since it is currently adjusting its urban spatial structure, urban design, and activity systems, Kaohsiung city be an excellent city to advocate the concept of climate sensitive design, as advocated in the Green-TOD approach. However, most of the current research projects concerning sustainable cities and TOD concentrate on strategic and theoretical discussion, and relatively little importance has been placed on scientific investigation into building environments and microclimate environments in rail station areas.

To understand the pedestrian wind environment - which has been created by development that occurred after the underground of Kaohsiung railway was built - the data of Wind Tunnel Test was used to verify the CFD simulation. The results proved the credibility of the simulation. Therefore, this study employs a scientific simulation approach to evaluating the wind environment around the Kaohsiung rail station using the CFD model. In this study, blocks surrounding the station were designed using two kinds of development: roadside-based development and street-block-based development. After comparing the CFD simulation results of the different prevailing winds - southerly and northwesterly-during two high traffic periods, it was found that street-block-based development created a better pedestrian wind environment. Furthermore, considering the same FAR and the wind direction of prevailing winds, it was found to be possible to create a wind environment suitable for pedestrians by adjusting the building heights and layouts in the street-block-based development.

These results show that building mass influences the local wind environment. This study also found that the local wind environment is related to several urban design measures. Therefore, considering the direction of the prevailing winds and the distributions of the buildings on both the windward and leeward sides, this study includes various discussions of urban design measure such as street block design, building mass control, and setting of open spaces; and detailed urban design methods such as building mass size, building height, building layout, and building lines. Although the total floor areas were the same in all cases, it was shown in the simulation results that the height and size of each building in the construction site has a great influence on the wind environment. Better ventilation could be created for pedestrians through proper management of architecture and city planning.

\section{References}

Atkinson-Palombo, C., \& Kuby, M. J. (2011). The geography of advance transit-oriented development in metropolitan Phoenix. Journal of Transport Geography, 19, 189-199. http://dx.doi.org/10.1016/j.jtrangeo.2010.03.014

Baruch, G. (1998). Climate consideration in building and urban design. New York: Van Nostrand Reinhild. Bernick, M., \& R. Cervero. (1997). Transit Village in the 21st Century. New York: Mc-Graw-Hill.

Blocken, B., Janssen, W. D., \& Hooff, T. (2012). CFD simulation for pedestrian wind comfort and wind safety in urban areas: General decision framework and case study for the Eindhoven University campus. Environmental 
Modelling \& Software, 30, 15-34. http://dx.doi.org/10.1016/j.envsoft.2011.11.009

Calthorpe, P. (1993). The next American metropolis: ecology, community, and the American dream. New York: Princeton Architectural Press.

Capeluto, I. G., \& Yezioro, A. (2003). Climatic aspects in urban design - a case study. Building and Environment, 38, 827-835. http://dx.doi.org/10.1016/S0360-1323(02)00063-X

Cervero, R. (2002). Built environments and mode choice: toward a normative framework. Transportation Research Part D: Transport and Environment, 7 (4), 265-284. http://dx.doi.org/10.1016/S1361-9209(01)00024-4

Cervero, R., \& Day, J. (2008). Suburbanization and transit-oriented development in China. Transport Policy, 15 (5), 315-323. http://dx.doi.org/10.1016/j.tranpol.2008.12.011

Hsieh, C. M., Chen, H., Ooka, R., Yoon, J., Kato, S., \& Miisho, K. (2010). Simulation analysis of site design and layout planning to mitigate thermal environment of riverside residential development. Building Simulation, 3, 51-61. http://dx.doi.org/10.1007/s12273-010-0306-7

IOT, MOTC (Institute of transportation, Ministry of transportation and communications). (2010). Hazard Prevention and Safety Management of Underground Traffic Facilities. Taipei.

Kubota, T., Miura, M., Tominaga, Y., \& Mochida, A. (2008). Wind tunnel tests on the relationship between building density and pedestrian-level wind velocity: Development of guidelines for realizing acceptable wind environment in residential neighborhoods. Building and Environment, 43 (10), 1699-1708. http://dx.doi.org/10.1016/j.buildenv.2007.10.015

Li, F., Liu, X., Hu, D., Wang, R., Yang, W., Li, D., \& Zhao, D. (2009). Measurement indicators and an evaluation approach for assessing urban sustainable development: A case study for China's Jining City. Landscape and Urban Planning, 90 (3-4), 134-142. http://dx.doi.org/10.1016/j.landurbplan.2008.10.022

Lin, J. J., \& Gau, C. C. (2006). A TOD planning model to review the regulation of allowable development densities around subway stations. Land Use Policy, 23 (3), 353-360. http://dx.doi.org/10.1016/j.landusepol.2004.11.003

Loo, B. P. Y., Chen, C., \& Chan, E. T. H. (2010). Rail-based transit-oriented development: Lessons from New York City and Hong Kong. Landscape and Urban Planning, 97 (3), 202-212. http://dx.doi.org/10.1016/j.landurbplan.2010.06.002

Millward, H. (2004). Urban containment strategies: A case-study appraisal of plans and policies in Japanese, British, and Canadian cities. Land Use Policy, 23 (4), 473-485. http://dx.doi.org/10.1016/j.landusepol.2005.02.004

Mochida, A., \& Lun, I. Y. F. (2008). Prediction of wind environment and thermal comfort at pedestrian level in urban area. Journal of Wind Engineering and Industrial Aerodynamics, 96 (10-11), 1498-1527. http://dx.doi.org/10.1016/j.jweia.2008.02.033

$\mathrm{Ng}$, E. (2009). Policies and technical guidelines for urban planning of high-density cities - air ventilation assessment (AVA) of Hong Kong. Building and Environment, 44 (7), 1478-1488. http://dx.doi.org/10.1016/j.buildenv.2008.06.013

Ng, E., Yuana, C., Chen, L., Rena, C., \& Fung, J. C. H. (2011). Improving the wind environment in high-density cities by understanding urban morphology and surface roughness: A study in Hong Kong. Landscape and Urban Planning, 101 (1), 59-74. http://dx.doi.org/10.1016/j.landurbplan.2011.01.004

Nijkamp, P., \& Perrels, A. (1994). Sustainable cities in Europe. London: Earthscan.

Rafailidis, S. (1997). Influence of building areal density and roof shape on the wind characteristics above a town. Boundary-Layer Meteorology, 85 (2), 288-271. http://dx.doi.org/10.1023/A:1000426316328

Ryua, Y., Kimb, S., \& Lee, D. (2009). The impacts of ventilation strategies and facade on indoor thermal environment for naturally ventilated residential buildings in Singapore. Building and Environment, 44 (1), 18-26.

Sung, H., \& Oh, J. T. (2011). Transit-oriented development in a high-density city: Identifying its association with transit ridership in Seoul, Korea. Cities, 28 (1), 70-82. http://dx.doi.org/10.1016/j.cities.2010.09.004

Stavrakakis, G. M., Koukou, M. K., Vrachopoulos, M. G., \& Markatos, N. C. (2008). Natural cross-ventilation in buildings: Building-scale experiments, numerical simulation and thermal comfort evaluation. Energy and Buildings, 40 (9), 1666-1681. http://dx.doi.org/10.1016/j.enbuild.2008.02.022

Stathopoulos, T. (2006). Pedestrian level winds and outdoor human comfort. Journal of Wind Engineering and 
Industrial Aerodynamics, 94 (11), 769-780. http://dx.doi.org/10.1016/j.jweia.2006.06.011

Tominaga, Y., Mochida, A., Yoshie, R., Kataoka, H., Nozu, T., Yoshikawa, M., \&Shirasawa, T. (2008). AIJ guidebook for practical applications of CFD to pedestrian wind environment around buildings. Journal of Wind Engineering and Industrial Aerodynamics, 96 (10-11), 1749-1761 http://dx.doi.org/10.1016/j.jweia.2008.02.058

Walmsley, A. (2006). Greenways: multiplying and diversifying in the 21 st century. Landscape and Urban Planning, 76 (1-4), 252-290. http://dx.doi.org/10.1016/j.landurbplan.2004.09.036

Willemsen, E., \& Wisse, J. A. (2007). Design for wind comfort in The Netherlands: Procedures, criteria and open research issues. Journal of Wind Engineering and Industrial Aerodynamics, 95 (9-11), 1541-1550. http://dx.doi.org/10.1016/j.jweia.2007.02.006

Wu, K. L. (2009). The Urban Design Strategic Planning of the corridor of the underground development of kaoshung railway system. Kaoshung City Government.

Wu, K. L. (2009). The Theory and Practice of Sustainable and ecological Communities. Zhan Shi Publisher.

Xie, H. M., Huang, Z., \& Wang, J. (2006). The impact of urban street layout on local atmospheric environment. Building and Environment, 41 (10), 1352-1363. http://dx.doi.org/10.1016/j.buildenv.2005.05.028

Yuan, C., \& Ng, E. (2012). Building porosity for better urban ventilation in high-density cities - A computational parametric study. Building and Environment, 50, 176-189. http://dx.doi.org/10.1016/j.buildenv.2011.10.023

Zhang, A., Gao, C., \& Zhang, L. (2005). Numerical simulation of the wind field around different building arrangements. Journal of Wind Engineering and Industrial Aerodynamics, 93 (12), 891-904. http://dx.doi.org/10.1016/j.jweia.2005.09.001

Table 1. Boundary conditions

\begin{tabular}{|c|c|c|}
\hline & Morning (7:01-9:00) & Afternoon (15:01-21:00) \\
\hline Inlet/Outlet & $\mathrm{S}$ & 2.88 \\
\hline Wind velocity $(\mathrm{m} / \mathrm{s})$ & 2.33 & Navier-Stokes equations \\
\hline CFD scheme & Direct numerical simulation(DNS): Central difference scheme \\
\hline Governing equations & $1500 \mathrm{~m}(\mathrm{~N}-\mathrm{S}) \times 1500 \mathrm{~m}(\mathrm{E}-\mathrm{W}) \times 600 \mathrm{~m}=135 \times 10^{7} \mathrm{~m}^{3}$ \\
\hline Boundary volume $(\mathrm{X} \times \mathrm{Y} \times \mathrm{Z})$ & $2,946,900 \mathrm{meshes}$ \\
\hline Total mesh number & $14 \mathrm{~m}$ \\
\hline Reference height $(\delta)$ & 0.27 \\
\hline Power law value $(\alpha)$ & $12 \mathrm{~m}$ \\
\hline Roughness height $\left(\mathrm{Z}_{\mathrm{b}}\right)$ & $22^{\circ} 38^{\prime} 19^{\prime \prime} \mathrm{N}, 120^{\circ} 18^{\prime} 7^{\prime \prime} \mathrm{E}$ \\
\hline Location & \multicolumn{2}{|c|}{} \\
\hline
\end{tabular}

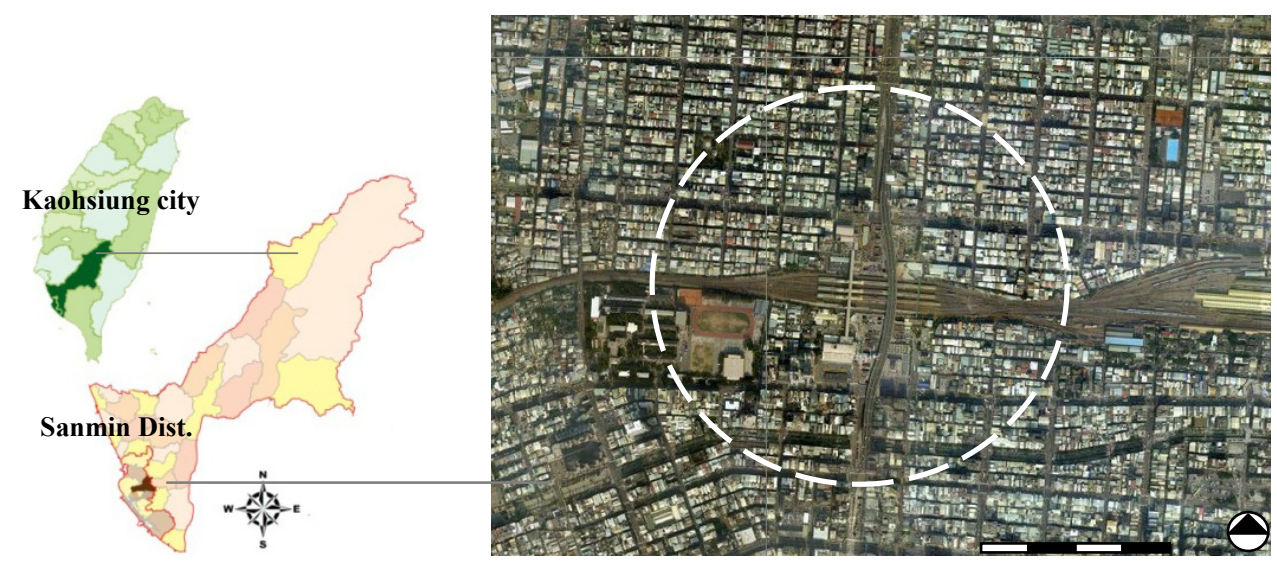

Figure 1. Kaohsiung railway station (Source: Google Earth) 


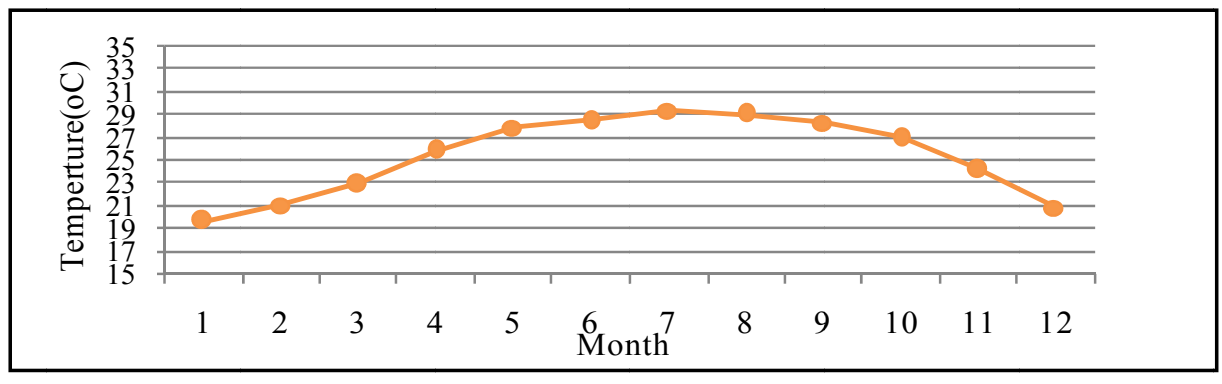

(a)

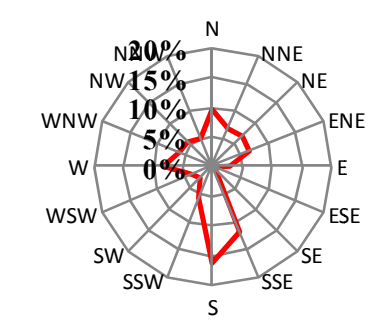

(b)

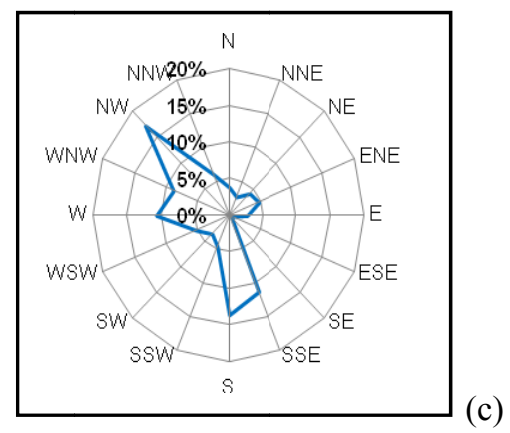

Figure 2. Meteorological data analysis of Kaohsiung city (data analysis from 2001 to 2010): (a) Air temperature changes (monthly average) in Kaohsiung city in one year. (b) Frequency (\%) of wind directions from 07:01-09:00; (c) Frequency (\%) of wind direction from 15:01-21:00

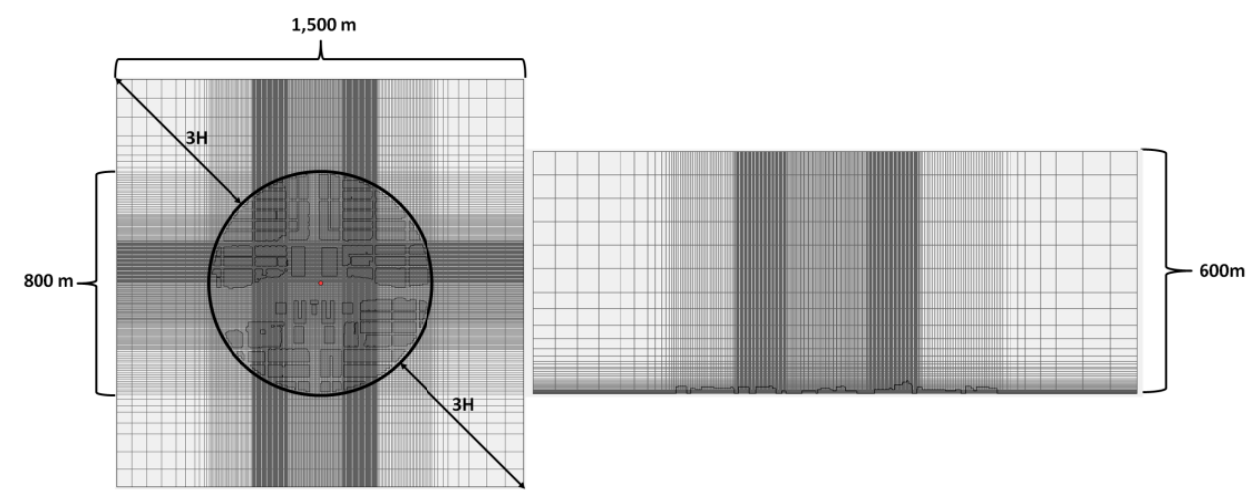

Figure 3. Geometry of CFD simulations

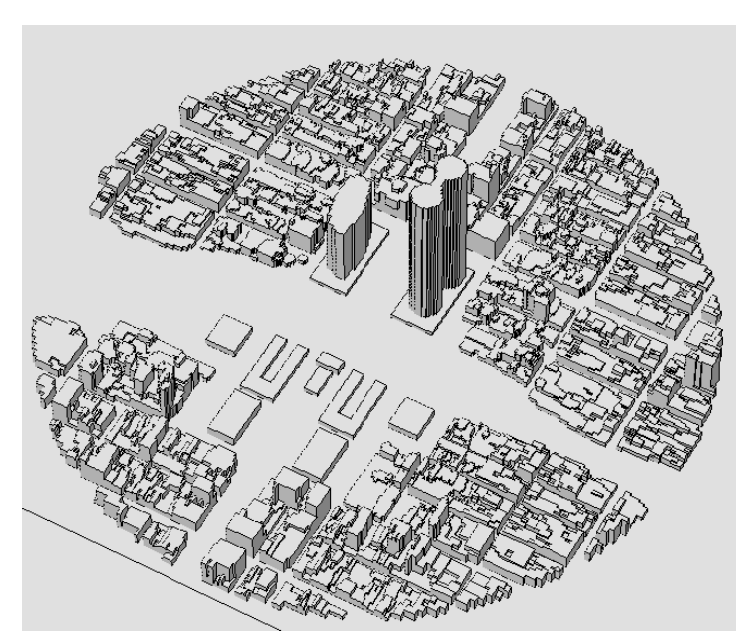

Figure 4. Scheduled development 


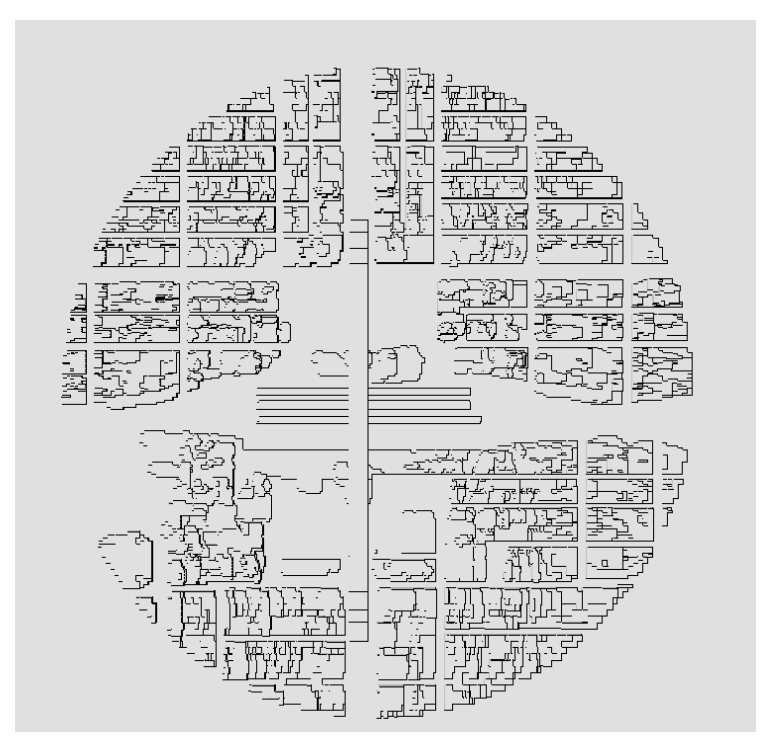

Figure 5. Focus areas
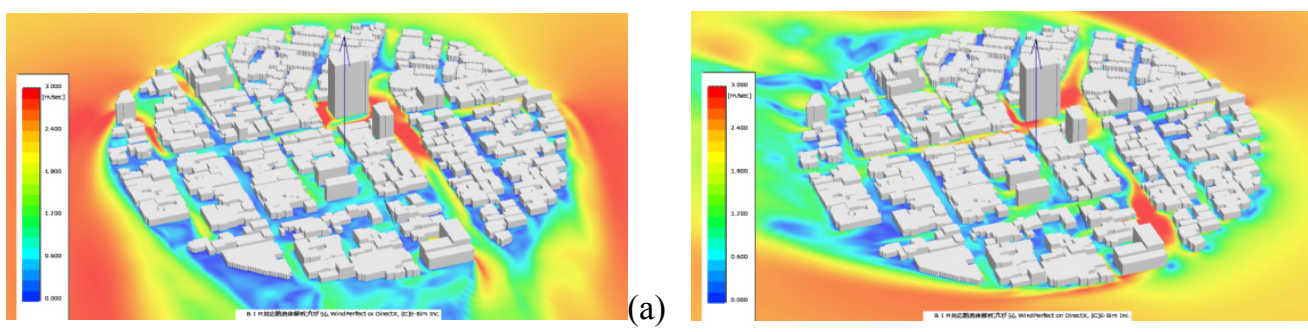

(b)

Figure 6. Simulation results of the Wind Tunnel Test: (a) West wind; (b) NNE wind
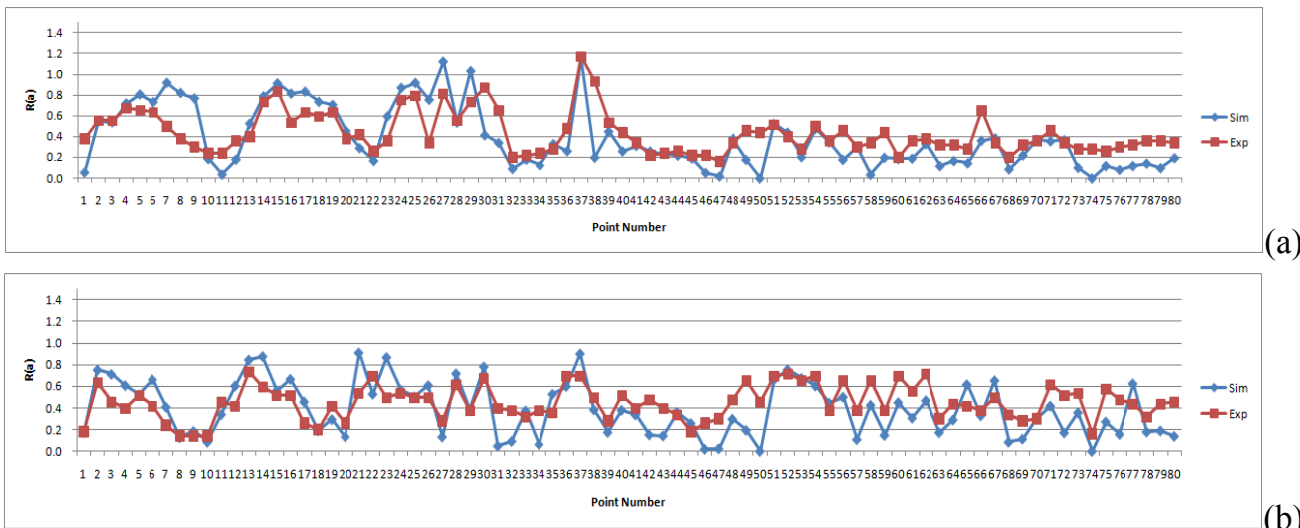

Figure 7. Comparing the inflow wind speed of the simulation and Wind Tunnel Test $(Z=2 \mathrm{~m})$ :

(a)West wind; (b) NNE wind 

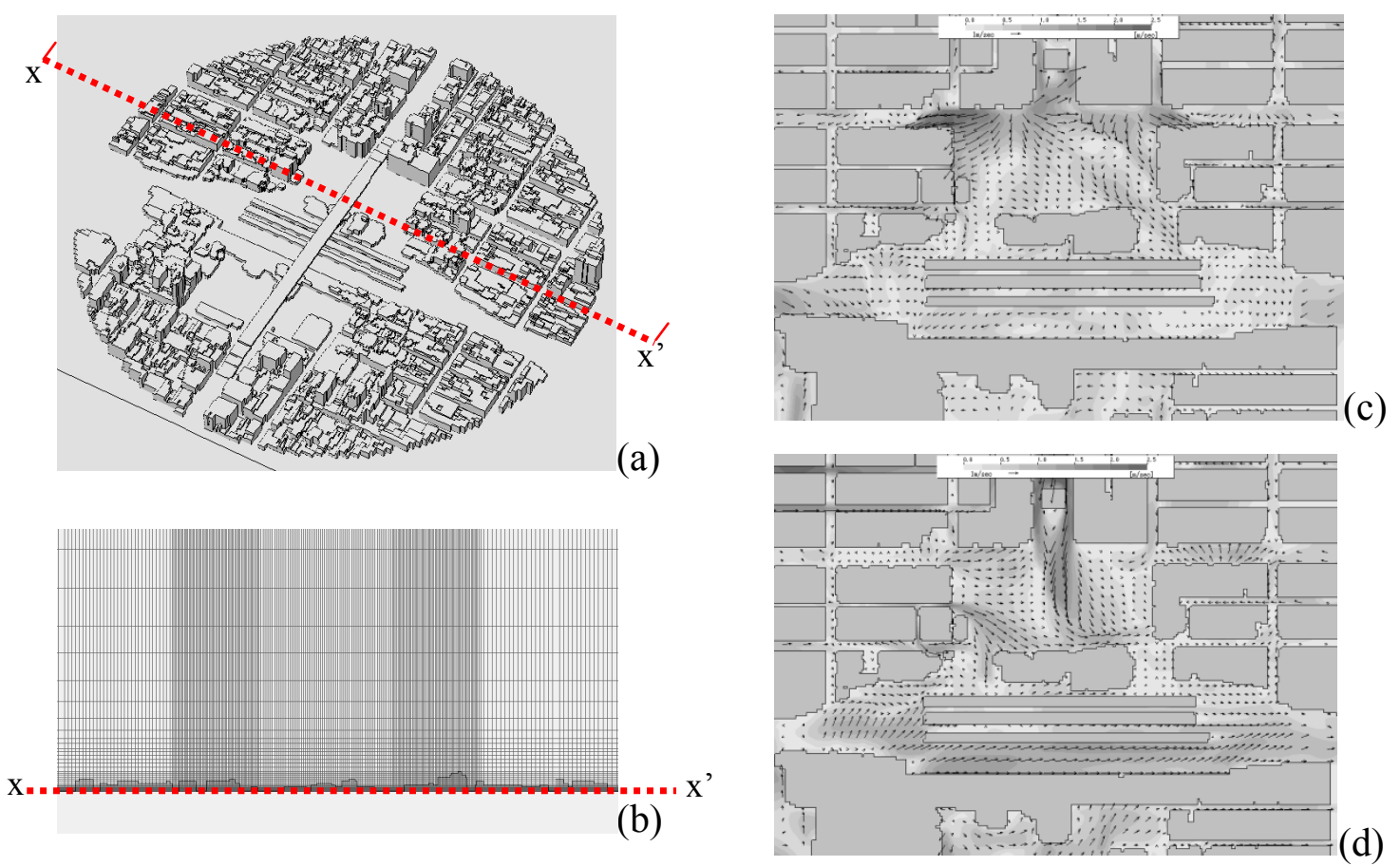

Figure 8. The wind distribution for Case 0 (at a height of $1.5 \mathrm{~m}$ ): (a) 3D vertical view of the whole area; (b) transect map from point $\mathrm{x}$ to $\mathrm{x}$ '; (c) profile drawing of wind direction $\mathrm{S}$; (d) profile drawing of wind direction NW
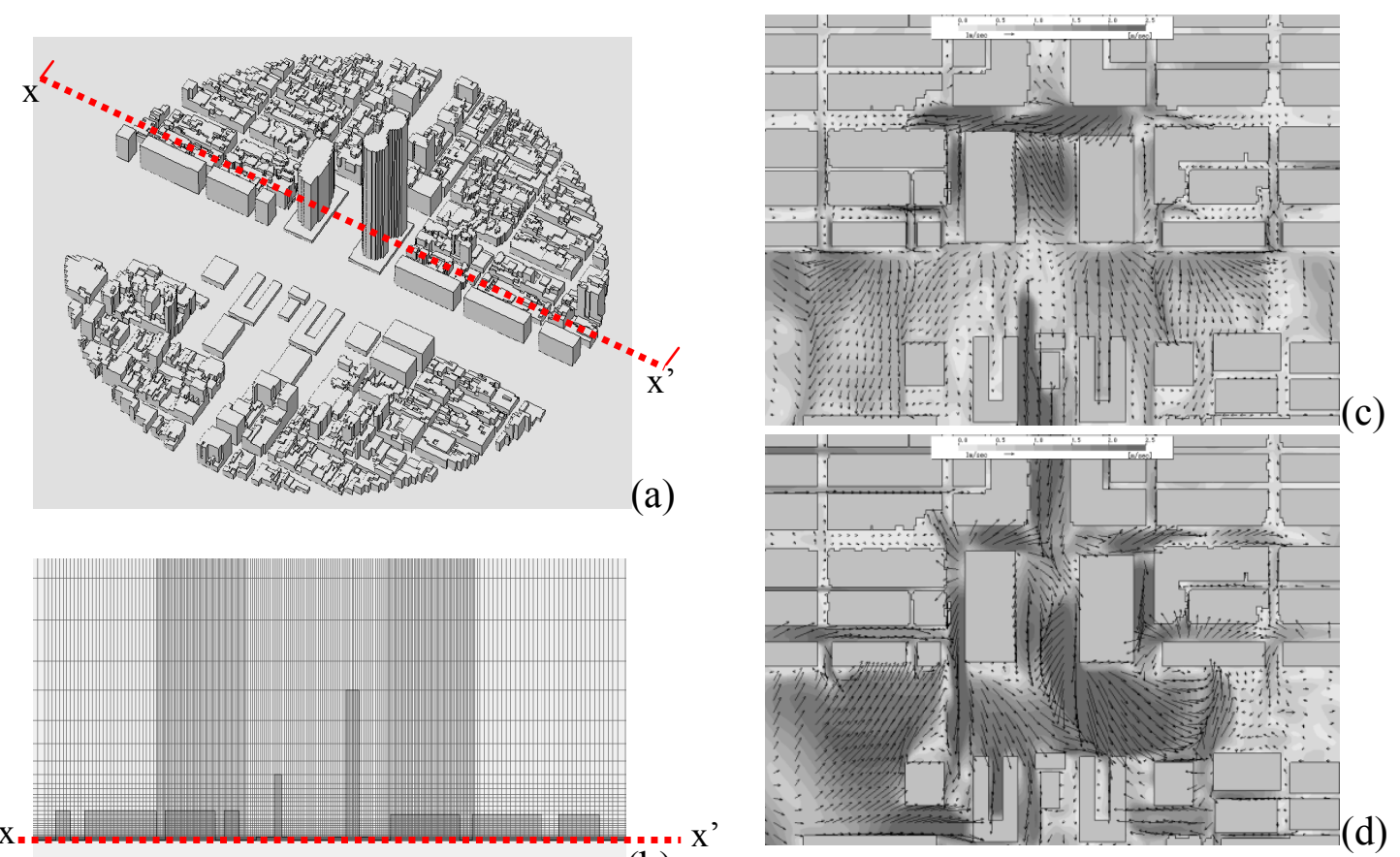

(b)

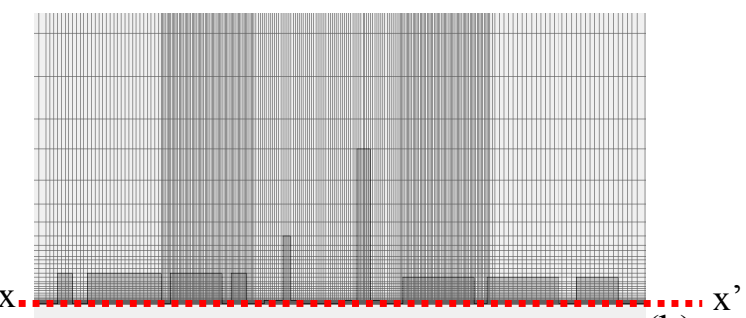

Figure 9. The wind distribution of Case 1 (at a height of 1.5m): (a) 3D vertical view of the whole area; (b) transect map from point $\mathrm{x}$ to $\mathrm{x}$; (c) profile drawing of wind direction $\mathrm{S}$; (d) profile drawing of wind direction NW 

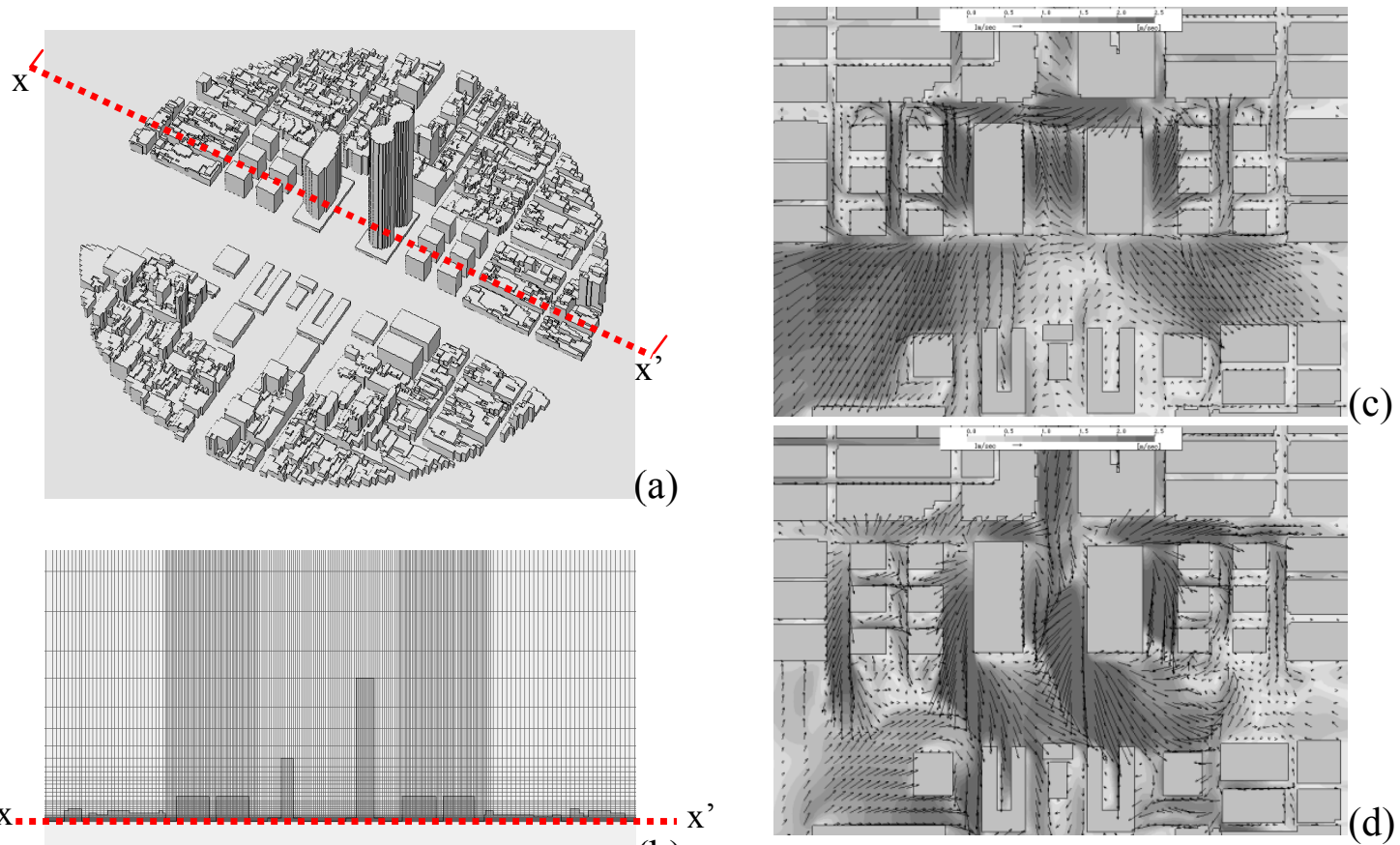

(b)

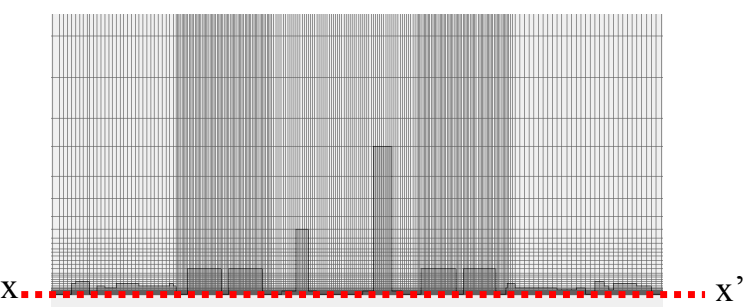

Figure 10. The wind distribution in Case 2 (at a height of 1.5m): (a) 3D vertical view of the whole area; (b) transect map from point $\mathrm{x}$ to $\mathrm{x}$ '; (c) profile drawing of wind direction $\mathrm{S}$; (d) profile drawing of wind direction NW
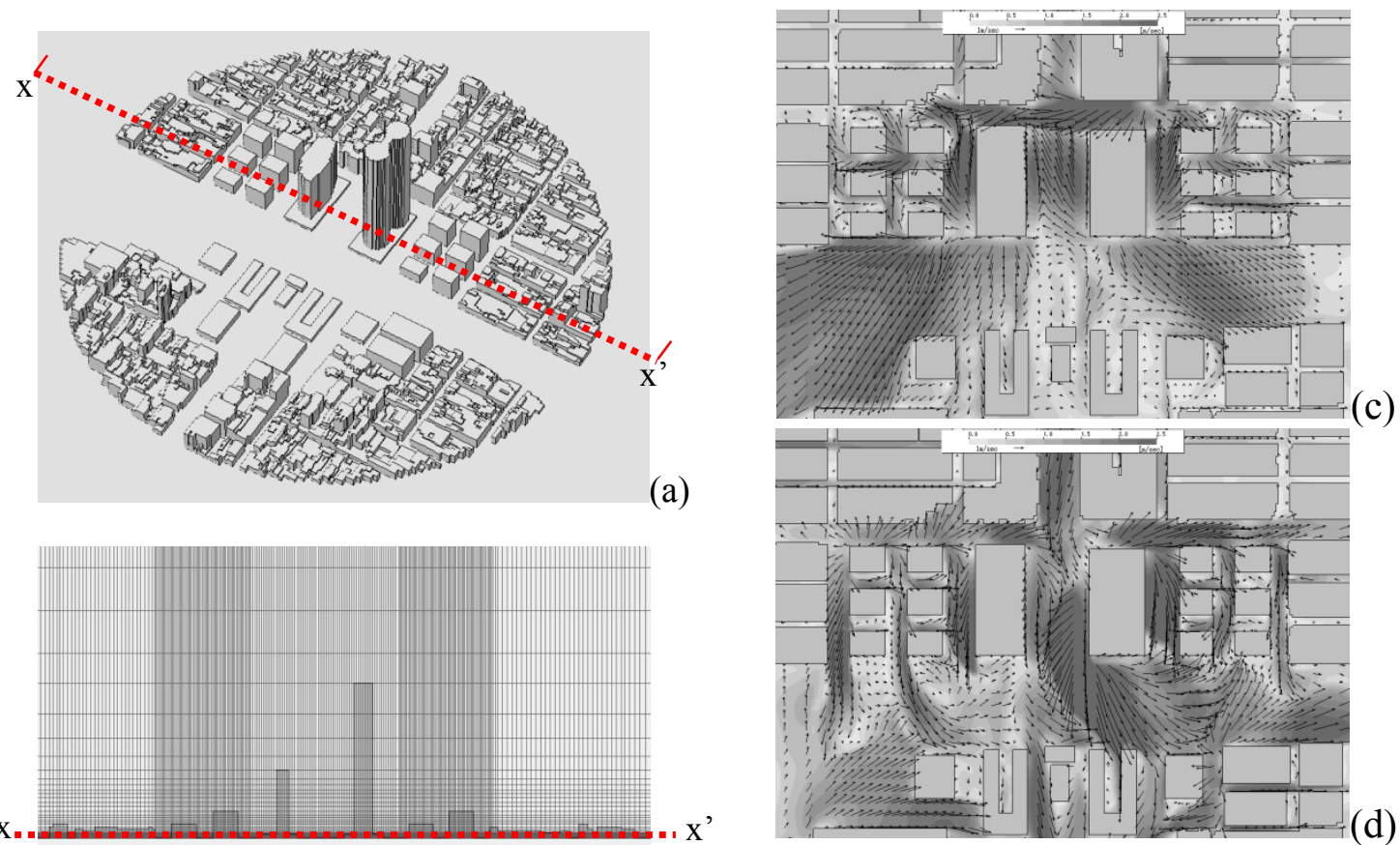

(b)

Figure 11. The wind distribution for Case 3 (at a height of 1.5m): (a) 3D vertical view of the whole area; (b) transect map from point $\mathrm{x}$ to $\mathrm{x}$ '; (c) profile drawing of wind direction $\mathrm{S}$; (d) profile drawing of wind direction NW 

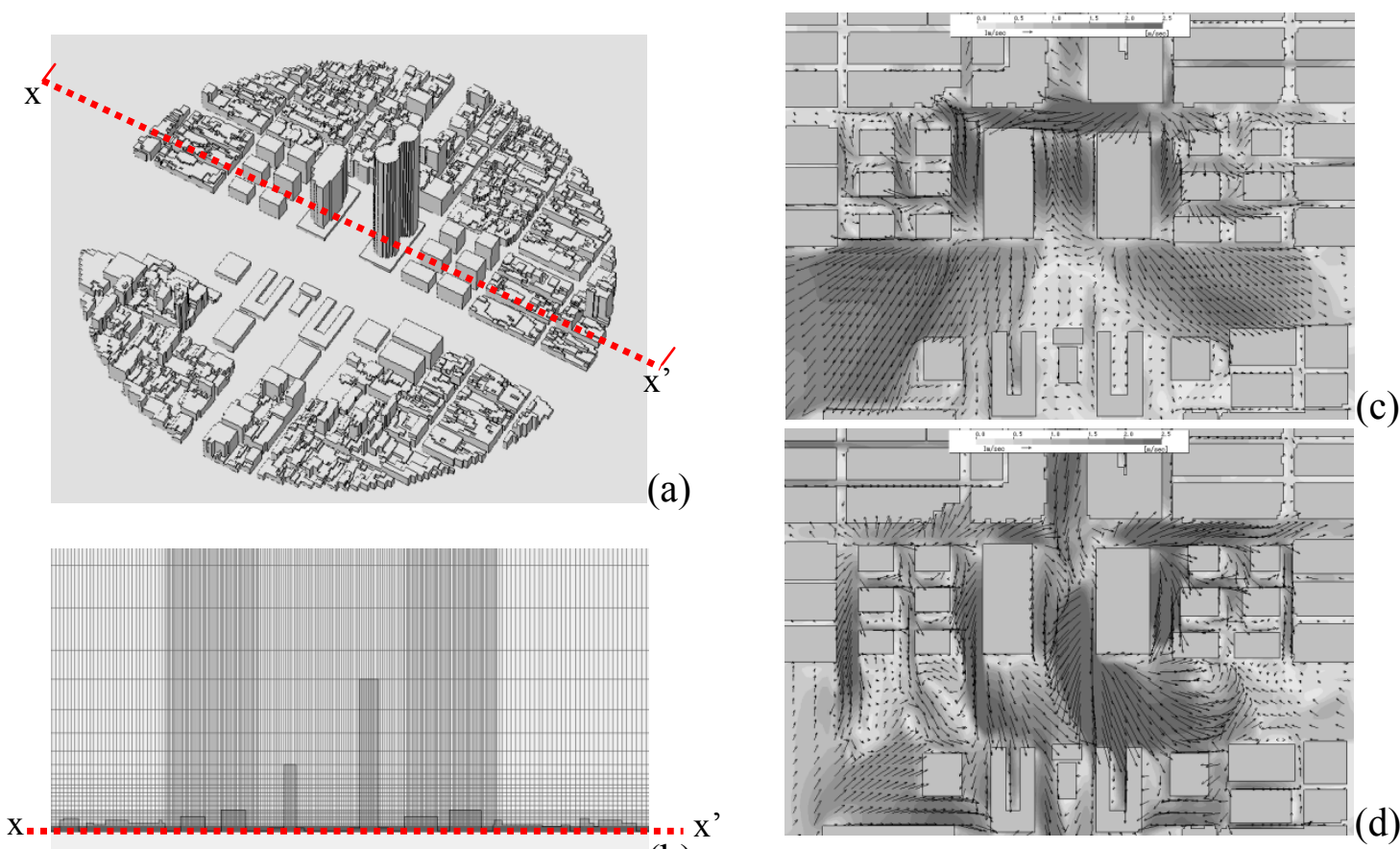

(b)

Figure 12. The wind distribution for Case 4 (at a height of $1.5 \mathrm{~m}$ ): (a) 3D vertical view of the whole area; (b) transect map from point $\mathrm{x}$ to $\mathrm{x}^{\prime}$; (c) profile drawing of wind direction $\mathrm{S}$; (d) profile drawing of wind direction NW

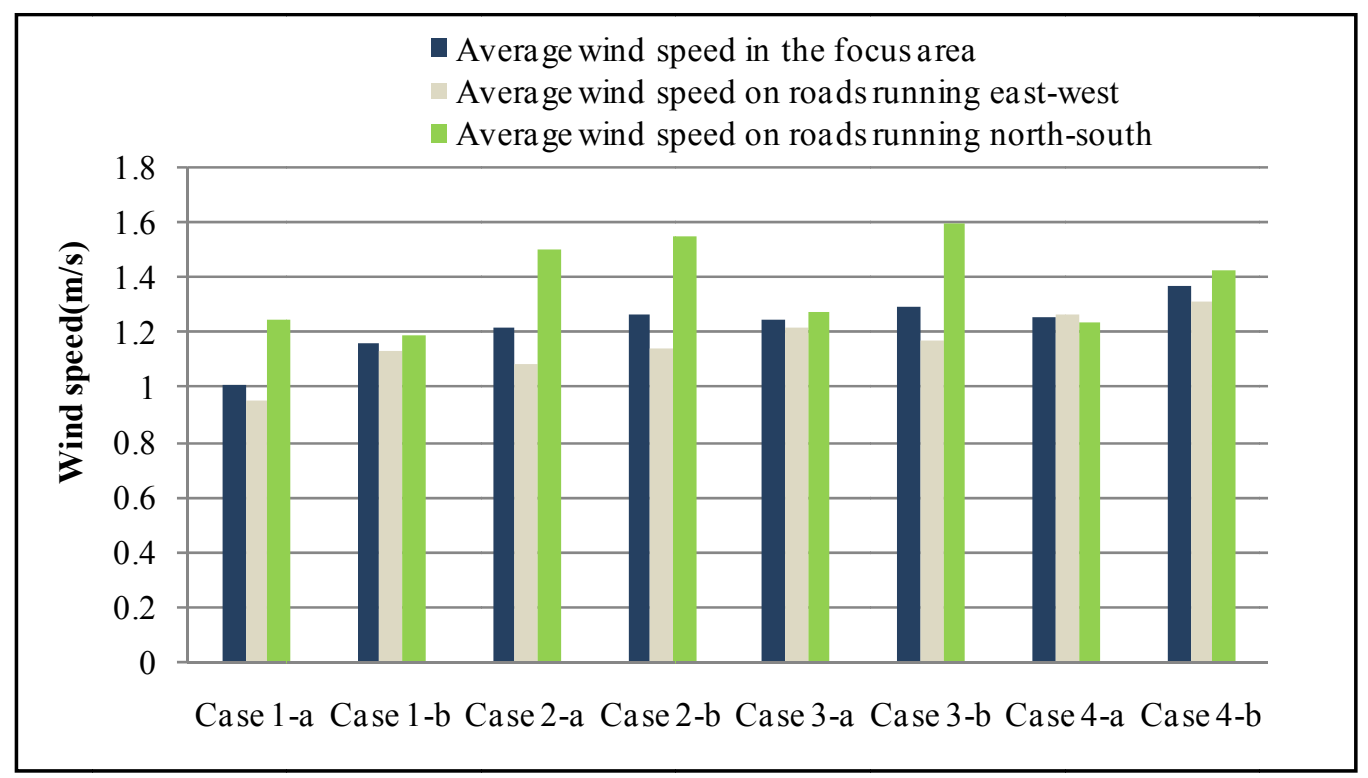

Figure 13. Simulation results in each case 